\title{
EFEITO DO TRATAMENTO QUÍMICO SOBRE A QUALIDADE FISIOLÓGICA E SANITÁRIA DE SEMENTES DE ARROZ COM DIFERENTES GRAUS DE UMIDADE ${ }^{1}$
}

\author{
CLARISSA SANTOS DA SILVA², ORLANDO ANTONIO LUCCA FILHO ${ }^{3}$, \\ PAULO DEJALMA ZIMMER ${ }^{3}$, ROBERTO MOURA BONINI FILHO ${ }^{4}$
}

\begin{abstract}
RESUMO - Este trabalho foi conduzido com objetivo de analisar o efeito do tratamento químico sobre a qualidade fisiológica e sanitária de sementes de arroz com diferentes graus de umidade durante o período de armazenamento. Foram utilizados dois lotes de sementes da cultivar EL PASO 144, com diferentes graus de umidade e níveis de sanidade. Para a formulação da calda fungicida foram adicionados $10 \mathrm{~mL}(1 \%), 20 \mathrm{~mL}(2 \%)$, e $30 \mathrm{~mL}(3 \%)$ de água em mistura com fungicida Carboxin/Thiram (300 mL.100 kg ${ }^{-1}$ de sementes). Iguais porcentagens de água, sem adição do fungicida, além de uma testemunha, constituíram os sete tratamentos. Após, foram embaladas em recipientes herméticos, e armazenadas por oito meses em temperatura ambiente. Foram avaliados o grau de umidade das sementes, a germinação, o vigor e a sanidade. Para avaliação bioquímica das sementes, através da técnica de eletroforese de sistemas enzimáticos, foi determinada a atividade das enzimas fosfatase ácida, álcool desidrogenase, glutamato oxalacetato, transaminase, esterase e $\alpha$-amilase. $O$ delineamento estatístico utilizado foi o completamente casualizado, com três repetições. Os efeitos benéficos do tratamento fungicida sobre a qualidade fisiológica são evidentes logo após o tratamento das mesmas. Houve decréscimo na germinação e no vigor das sementes tratadas, intensificado a partir do $60^{\circ}$ dia de armazenamento. $\mathrm{O}$ fungicida utilizado no tratamento de sementes é eficiente na redução da incidência de fungos associados às mesmas. A alta umidade da semente associada ao fungicida acelera o processo de deterioração durante o armazenamento em embalagem hermética. Não foi possível detectar efeito do fungicida na expressão das enzimas em sementes viáveis.
\end{abstract}

Termos para indexação: Oryza sativa L., sanidade, vigor, armazenamento, Carboxin/Thiram.

\section{EFFECT OF CHEMICAL TREATMENT ON THE PHYSIOLOGICAL AND SANITARY QUALITY OF RICE SEEDS WITH DIFFERENT MOISTURE CONTENTS}

\begin{abstract}
The objective of this study was to evaluate the effect of chemical treatments during storage on the health and physiological quality of rice seeds with different moisture contents. Two rice seeds lots were used, cv EL PASO 144, with different moisture and health levels. To formulate the fungicide, $10 \mathrm{~mL}(1 \%), 20 \mathrm{~mL}(2 \%)$ and $30 \mathrm{~mL}(3 \%)$ of water were mixed with the fungicide Carboxin/Thiram $(300 \mathrm{~mL} / 100 \mathrm{Kg}$ of seeds). The same water percentages, without addition of the fungicide, and also a control, constituted the seven treatments. The seeds were stored in hermetically-sealed recipients for eight months and were subsequently evaluated for moisture content, standard germination, vigor and health. Biochemical evaluation of the seeds was made by using electrophoresis of enzymatic systems to determine the activity of the enzymes:
\end{abstract}

\footnotetext{
${ }^{1}$ Submetido em 03/04/2009. Aceito para publicação em 21/03/2011.

${ }^{2}$ Pesquisadora da Universidade da Região da Campanha Cx. postal 310, 96400-350, Bagé, RS. E- mail clarissas_s@hotmail.com.
}

${ }^{3}$ Prof. Adjunto Dr., Depto Fitotecnia - FAEM/ UFPel C.P. 354, CEP: 96010-900, Pelotas- RS

\footnotetext{
${ }^{4}$ Graduando em Agronomia FAEM/UFPel
} 
acid phosphatasis, alcohol dehydrogenasis, glutamate oxalacetate transaminase, esterase and $\alpha$-amylase. The statistical design was of completely randomized blocks with three replications. The beneficial effect of the fungicide on physiological quality was evident immediately after the seed treatment. The results showed that the germination and vigor of treated seeds decreased after 60 days storage. The fungicide used in the seed treatment was efficient in reducing fungal incidence on the rice seeds. The high moisture associated with the fungicide applied accelerated the deterioration of seeds stored hermetically. It was not possible to identify the effect of the fungicide on the expression of enzymes in viable seeds.

Index terms: Oryza sativa L., sanitary, vigor, storage, Carboxin/Thiram.

\section{INTRODUÇÃO}

O arroz irrigado (Oryza sativa L.) é a cultura mais extensamente cultivada no mundo, constituindo-se a base da alimentação de vários povos, inclusive o brasileiro. O Estado do Rio Grande do Sul contribui com 50\% da produção nacional desse cereal (Embrapa, 2005). No entanto, a necessidade de maior produção de alimentos no mundo, em face ao acentuado crescimento da população no presente século, fez com que fronteiras agrícolas fossem substancialmente aumentadas e novas tecnologias de produção desenvolvidas e incorporadas ao setor produtivo.

Em conseqüência do uso intensificado das áreas de cultivo, sérios problemas de natureza sanitária foram criados. Um desses problemas consiste no fato de que agentes fitopatogênicos são capazes de associar-se às sementes de seus hospedeiros, podendo, a partir daí, sobreviver por longos períodos, ser disseminados a diferentes partes da terra e causar sérios prejuízos.

A ocorrência de doenças é um dos maiores fatores de restrição à produção. A planta de arroz, em qualquer fase de desenvolvimento, está sujeita a doenças que reduzem tanto a qualidade quanto a quantidade final do produto. Entre os prejuízos diretos, causados pelas doenças em arroz, incluem-se a redução do estande de plantas, grãos manchados, menor número e/ou tamanho de grão e redução geral na eficiência produtiva dessas plantas (Miura, 2002).

Um grande número de microrganismos são transportados e introduzidos em outras áreas através de sementes, sendo os fungos os que causam o maior número de enfermidades nas plantas e que ocorrem com maior freqüência do que bactérias e nematóides (Zapata, 1985).
O controle de algumas dessas contaminações pode ser feito através do tratamento de sementes com fungicida, enquanto para outras os resultados são negativos ou incompletos, tornando-se positivos quando usados de forma integrada com outros métodos de controle, notadamente bom manejo de práticas culturais, cultivares resistentes e agentes físicos e biológicos (Ribeiro, 1996).

No controle integrado de doenças de plantas, o tratamento de sementes constitui uma medida valiosa pela sua simplicidade de execução, baixo custo e eficácia sob vários aspectos. Porém, a simples opção de aplicar um fungicida e armazenar as sementes, ou aplicá-lo e semeálas imediatamente após o tratamento, exige cuidados, especialmente para não causar danos à própria semente. Além disso, o tratamento quando mal realizado, pode causar diminuição da qualidade fisiológica das sementes, principalmente se esta for armazenada. Isto ocorre em virtude das quantidades utilizadas para diluir o produto. Puzzi (1986) e Neergaard (1977) são categóricos em afirmar que o grau de umidade influencia diretamente a qualidade da semente armazenada, possibilitando o desenvolvimento de fungos, insetos e ácaros.

Neste contexto, este trabalho tem por objetivo analisar e descrever o efeito do tratamento químico sobre a qualidade fisiológica e sanitária das sementes de arroz cv. EL PASO 144 com diferentes graus de umidade, durante o período de oito meses de armazenamento, embaladas em recipientes herméticos.

\section{MATERIAL E MÉTODOS}

Foram utilizados dois lotes de sementes de arroz da cultivar EL PASO 144, com diferentes níveis de qualidade sanitária, provenientes de lavouras da região de Pelotas, 
produzidas na safra 2004/2005. Os lotes 1 e 2 apresentaram germinação de $91 \%$ e $89 \%$, pureza física mínima de $98 \%$ e umidade máxima de 13 e $16 \%$, respectivamente. O tratamento químico das sementes foi realizado cinco meses após a colheita das mesmas, utilizando-se o produto comercial, composto pela associação dos fungicidas Carboxin e Thiran, na dose de $300 \mathrm{~mL}$ por $100 \mathrm{~kg}$ de sementes, de acordo com as Recomendações Técnicas de 1999.

Para a execução do experimento foram realizados sete tratamentos, nos quais as quantidades de água utilizadas foram baseadas no princípio deste estudo: aumentar a umidade das sementes, associada à utilização de fungicida, a fim de verificar seu comportamento após período de armazenamento.

As sementes foram separadas em porções de $1 \mathrm{~kg}$, recebendo os seguintes tratamentos:

T1: Testemunha, sem adição de água $-0 \%$

T2: Pulverização com $10 \mathrm{~mL}$ de água $-1 \%$

T3: Pulverização com $20 \mathrm{~mL}$ de água - 2\%

T4: Pulverização com $30 \mathrm{~mL}$ de água - 3\%

T5: Pulverização com $10 \mathrm{~mL}$ de água mais fungicida ( 3,0 $\mathrm{mL}$ de fungicida mais $7 \mathrm{~mL}$ de água) - $1 \%$

T6: Pulverização com $20 \mathrm{~mL}$ de água mais fungicida ( 3,0 mL de fungicida mais $17,0 \mathrm{~mL}$ de água) $-2 \%$

T7: Pulverização com $30 \mathrm{~mL}$ de água mais fungicida ( $3,0 \mathrm{~mL}$ de fungicida mais $27,0 \mathrm{~mL}$ de água) $-3 \%$

Após a pulverização as sementes foram homogeneizadas manualmente por agitação dentro de sacos plásticos, acondicionadas em garrafas de PVC de 2 litros e colocadas em caixas de isopor, onde permaneceram por oito meses à temperatura de $\pm 22^{\circ} \mathrm{C}$.

As sementes foram submetidas à determinação do grau de umidade e aos testes de germinação e vigor (teste de frio), que foram conduzidos no Laboratório de Análise de Sementes; o teste de sanidade, no Laboratório de Patologia de Sementes, e as análises de eletroforese no Laboratório de BioSementes na UFPel. As avaliações foram realizadas em cinco épocas diferentes: no início do armazenamento e a cada dois meses $(60,120,180$ e 240 dias $)$.

Para a determinação do grau de umidade foi utilizado o método da estufa a $105 \pm 3{ }^{\circ} \mathrm{C}$, conforme Brasil (1992).

Para a realização do teste de germinação foram utilizadas 200 sementes (4 repetições de 50 sementes), semeadas sobre uma folha de papel germitest dobrada e umedecida previamente com água destilada na proporção de 2,5 vezes o peso do papel. Em seguida, foi colocada outra folha de papel germitest dobrada sobre as sementes. Os rolos foram colocados no germinador à temperatura de $25 \pm 2{ }^{\circ} \mathrm{C}$. Foram realizadas duas contagens, aos $7 \mathrm{e}$ 14 dias, e os resultados foram expressos em porcentagem, após a obtenção da média aritmética das quatro repetições (Brasil, 1992).

Para a análise de vigor, foi utilizado o teste de frio conforme Krzyzanowski (1999). Utilizou-se o mesmo procedimento para o teste de germinação, sendo os rolos colocados em sacos plásticos fechados permanecendo em incubadora a $10{ }^{\circ} \mathrm{C}$ por sete dias. Após este período, os rolos foram transferidos para um germinador à temperatura de $25 \pm 2{ }^{\circ} \mathrm{C}$ e realizadas contagens aos 7 e 14 dias. Os resultados foram expressos através da média aritmética das quatro repetições, em números percentuais inteiros (Krzyzanowski et al, 1999).

Para o teste de sanidade, foi utilizado o método do papel de filtro ou "Blotter test" (Neergaard, 1977) até os 180 dias. Foram avaliadas 200 sementes, distribuídas em oito repetições de 25 sementes em caixas gerbox previamente desinfestadas com uma solução de hipoclorito de sódio a $1 \%$. Em cada gerbox foram colocadas duas folhas de papel filtro, umedecidas com água destilada até a saturação. Sobre elas foram distribuídas as sementes, as quais permaneceram em incubação por sete dias, sob temperatura de $20 \pm 2{ }^{\circ} \mathrm{C}$ e regime luminoso de 12 horas de luz e 12 horas de escuro. A iluminação foi obtida com lâmpadas fluorescente de 40W, dispostas sobre os gerbox a uma distância de $40 \mathrm{~cm}$. Após o período de incubação, as sementes foram avaliadas individualmente, utilizando-se um microscópio estereoscópio e um microscópio composto, quando necessário, para preparação de lâminas microscópicas.

Para a análise eletroforética das enzimas, 50 sementes por tratamento, foram semeadas em rolo de papel, e acondicionadas em germinador regulado a 25 ${ }^{\circ} \mathrm{C}$, segundo as Regras para Análise de Sementes (Brasil, 1992). O material vegetal (dez plântulas aleatórias) usado para extração de proteínas foi coletado quatro dias após implantação teste de geminação. As dez plântulas coletadas foram pesadas e o extrato vegetal de cada uma das amostras foi colocado em tubos eppendorf acrescidos de solução extratora (borato de lítio $0,2 \mu \mathrm{L}+$ triitrato $0,2 \mu \mathrm{L}(9: 1)$ juntamente com $0,15 \%$ de 2 -mercaptoetanol) na proporção $1: 3(\mathrm{p} / \mathrm{v})$ e macerado com o auxílio de um bastão de vidro esmerilhado. A técnica foi realizada em gel de poliacrilamida $7 \%$ obtido pela mistura de acrilamida, bis-acrilamida, tampão gel, temed e persufato de amônio $10 \%$. As soluções preparadas foram vertidas em placas 
de vidro $(160 \times 180 \times 2 \mathrm{~mm})$, onde, após a polimerização foram adicionados $20 \mu \mathrm{L}$ de cada amostra no gel, em orifícios feitos com auxílio de um pente de acrílico, e transferidos para as cubas eletroforéticas verticais mantidas em câmara fria com temperatura entre 4 e $6{ }^{\circ} \mathrm{C}$. As migrações eletroforéticas foram realizadas aplicandose uma diferença de potencial ao redor de 10 volts.cm ${ }^{-1}$ linear, deixando-se migrar até que a linha de frente, marcada pelo azul de bromofenol, atingisse $9 \mathrm{~cm}$ do ponto de aplicação.

Os géis foram revelados para os sistemas enzimáticos fosfatase ácida, álcool desidrogenase, glutamato oxalacetato transaminase, esterase e $\alpha$-amilase, conforme descrito Scandalios (1969) e Alfenas (1998). Após a revelação, os géis foram fixados em solução de glicerol $10 \%$ (v/v). A interpretação dos resultados foi baseada na análise visual dos géis de eletroforese, levando em consideração a presença/ausência de bandas eletroforéticas.

O modelo utilizado para realizar a análise estatística foi inteiramente casualizado, em arranjo fatorial (7 tratamentos e 5 épocas de avaliação) com três repetições. A análise foi efetuada com o programa para estatística WinStat 2.0 (Machado e Conceição, 2003) e, para a comparação das médias foi utilizado o teste de Tukey (5\%). Os dados referentes aos períodos de armazenaemento foram submetidos à análise de regressão polinomial.

\section{RESULTADOS E DISCUSSÃO}

Nas Tabelas 1 e 2 estão apresentados os graus de umidade das sementes nos diferentes tratamentos, registrados no pré-armazenamento (imediatamente após o tratamento) e aos $60,120,180$ e 240 dias de armazenagem, para os lotes 1 e 2 . Ao comparar-se o tratamento das sementes dos lotes 1 e 2 sem adição de água (T1) com os tratamentos que receberam $1 \%$ (volume/peso) de água ou calda fúngica (T2 e T5) no pré-armazenamento, observa-se aumento do grau de umidade de aproximadamente 0,9 pontos percentuais Já os que receberam $2 \%$ de água (T3 e T6) tiveram acréscimo de 1,5 pontos percentuais e com $3 \%$ de água (T4 e T7) o aumento foi de 2,3 pontos percentuais

Constata-se que, entre o pré-armazenamento e 240 dias de armazenamento, para os diversos tratamentos, houve um acréscimo de aproximadamente $1,7 \%$ no grau de umidade das sementes de ambos os lotes. Ressalta-se, no entanto, que as sementes do lote 2 possuíam umidade inicial bem mais elevada $(15,8 \%)$ quando comparada à do lote 1 (Tabela 1 ), que era de $12,8 \%$.

As sementes de ambos os lotes acondicionadas em recipientes herméticos tiveram sua atividade metabólica favorecida pelo elevado teor de água inicial e que não pode se difundir através do $\mathrm{PVC}$, acelerando, desta forma, o processo de respiração e queima de reservas, contribuindo para acelerar o processo de deterioração. Estudos realizados por Henning et al. (1995) também constataram que embalagens de plásticas (impermeáveis) são prejudiciais à qualidade das sementes com graus de umidade mais altos, independente do local de armazenamento.

Os resultados de germinação durante o período de armazenamento encontram-se nas Figuras 1 e 2. Verifica-se que imediatamente após o tratamento (préarmazenamento), as sementes dos dois lotes tratadas com fungicidas (T5, T6 e T7) apresentaram porcentagem de germinação superior às das não-tratadas $(\mathrm{T} 1, \mathrm{~T} 2, \mathrm{~T} 3$ e T4), excetuando-se o tratamento 7 no lote 2 (Figura 2). No entanto, esta superioridade é observada apenas logo após o tratamento, pois a partir deste período há redução nos percentuais germinativos em todos os tratamentos fungicidas, sendo este decréscimo mais acentuado e mais rápido nas sementes do lote 1 .

Ao analisar a porcentagem de germinação das sementes do lote 1 observa-se que houve perda de qualidade mais acentuada naqueles tratamentos que receberam maior volume de água (T4 e T7), indicando que a manutenção e/ou a redução menos acentudada da qualidade durante o período de armazenamento está associada ao menor conteúdo de água da semente. Entretanto, este comportamento não foi observado para os mesmos tratamentos do lote 2 , no qual até mesmo as sementes do T1 tiveram a qualidade reduzida a valores abaixo de $80 \%$. Tais diferenças podem ser atribuídas ao menor vigor inicial deste lote, assim como a maior incidência de fungos e percentagem maior de umidade.

O tratamento de sementes com fungicidas tem suas vantagens, como a erradicação de fungos patogênicos, mas pode também causar redução de qualidade quando fitotóxico. Além da fitotoxicidade causada pela dosagem excessiva, outros problemas podem estar associados ao tratamento de sementes. Alguns destes problemas foram discutidos por Menten (1996), que enfatiza que no tratamento de sementes antes do armazenamento o possível efeito fitotóxico do fungicida pode se acentuar, podendo ocorrer também diminuição da eficiência do mesmo. 


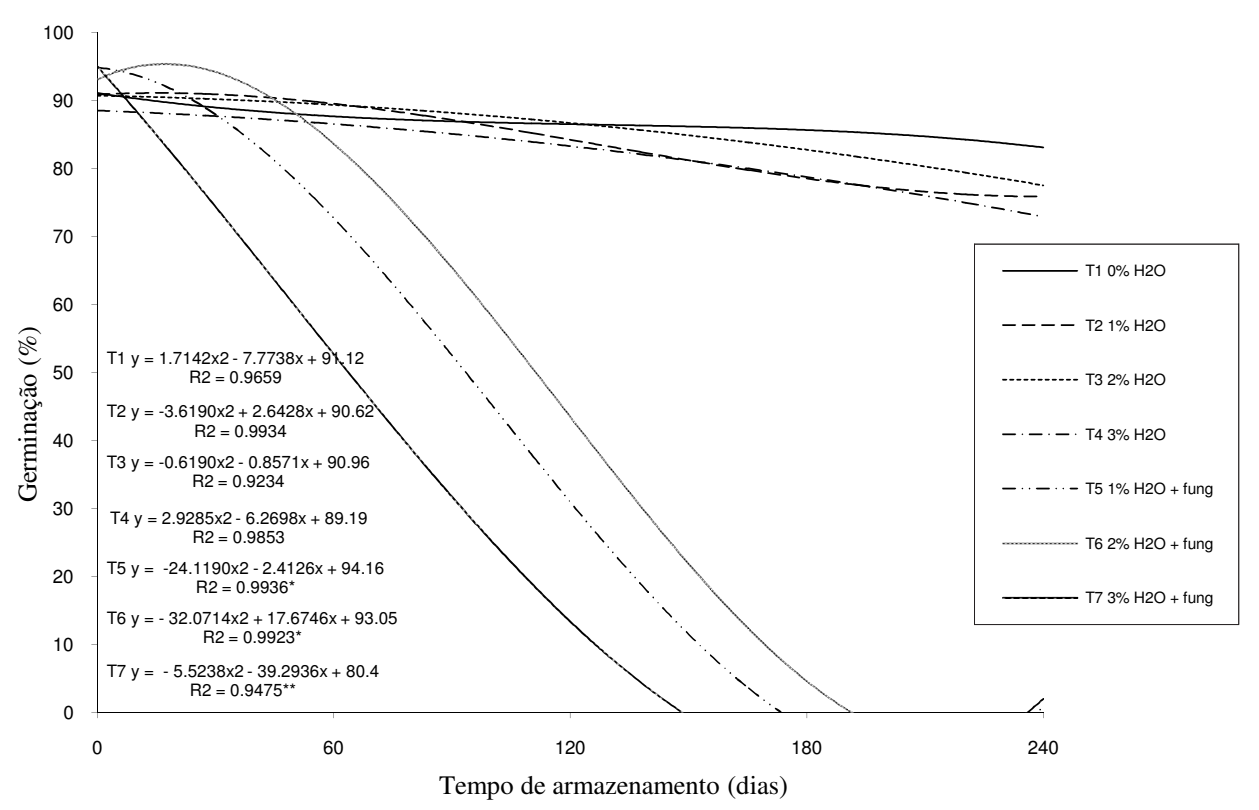

FIGURA 1. Porcentagem de germinação de sementes de arroz, cultivar EL PASO 144, lote 1, armazenadas hermeticamente durante oito meses a $\pm 22{ }^{\circ} \mathrm{C}$.

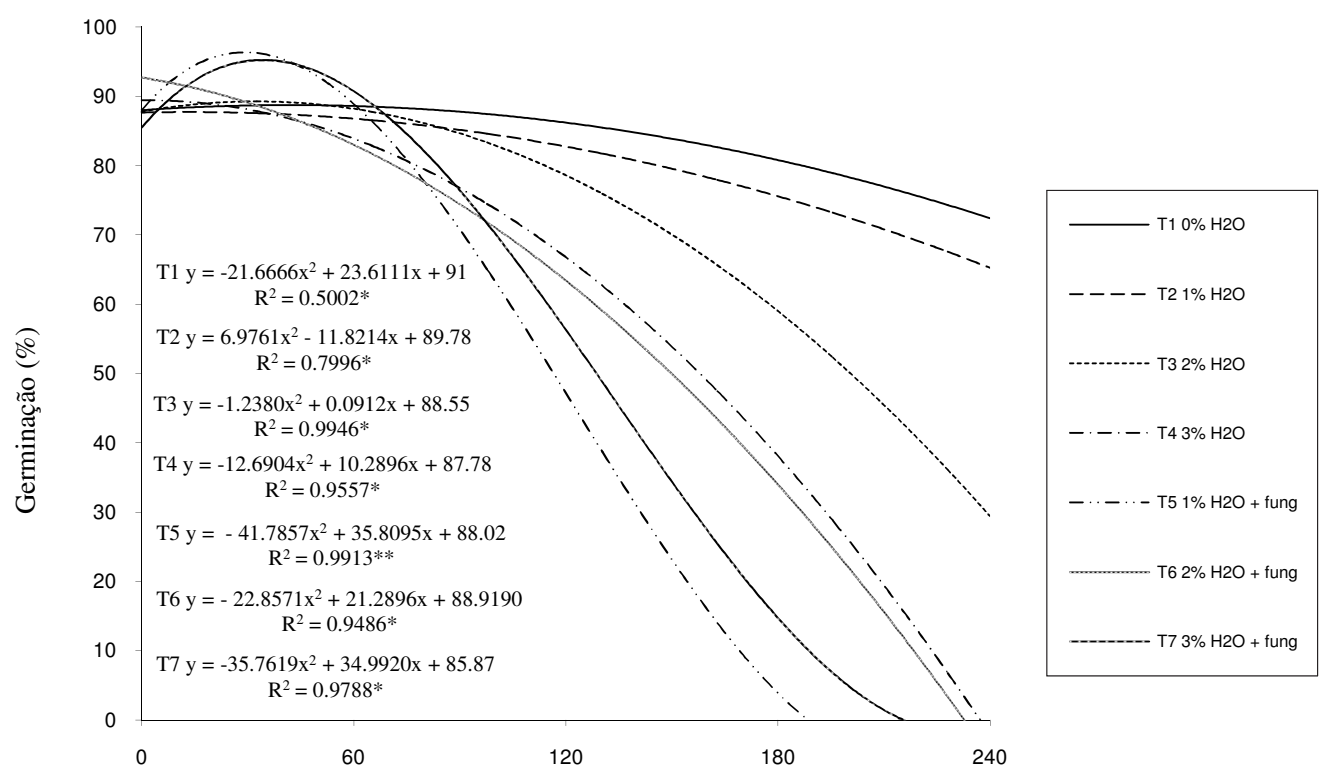

Tempo de armazenamento (dias)

FIGURA 2. Porcentagem de germinação de sementes de arroz, cultivar EL PASO 144, lote 2, armazenadas hermeticamente durante oito meses a $\pm 22{ }^{\circ} \mathrm{C}$. 
Com relação ao desempenho das sementes no teste de frio (Figuras 3 e 4) realizado no pré-armazenamento, observa-se que as sementes tratadas com fungicida (T5, T6 e T7) apresentaram maior vigor que as não-tratadas (T1, T2, T3 e T4), excetuando o tratamento 7 no lote 2 , que manteve o mesmo valor da testemunha.

Resultados semelhantes foram obtidos por Zorato e Henning (2001), onde tratamentos com Thiabendazole + Thiram e Carbendazin + Thiram aplicados às sementes de soja contribuíram para o aumento da germinação após 30 dias de armazenamento, tendo respostas superiores às sementes não-tratadas. Marcos-Filho e Souza (1983) verificaram que o tratamento fungicida antes do início do período de armazenamento pode beneficiar a conservação do vigor.

Aos 60 dias de armazenamento, pode-se verificar que sementes do lote 1 (Figura 3) tratadas com fungicidas (T5, T6 e T7) apresentaram redução no vigor em relação às não-tratadas. Observa-se também que após 120 dias de armazenamento, os níveis de vigor decaem severamente nos tratamentos com fungicida, alcançando valores próximos a $8 \%$. Aos 180 e 240 dias de armazenamento, as sementes tratadas mostram redução ainda maior no vigor, chegando a zero os valores de germinação. Contudo, em sementes sem tratamento, a redução da qualidade foi menos acentuada, confirmando os resultados obtidos no teste de germinação.

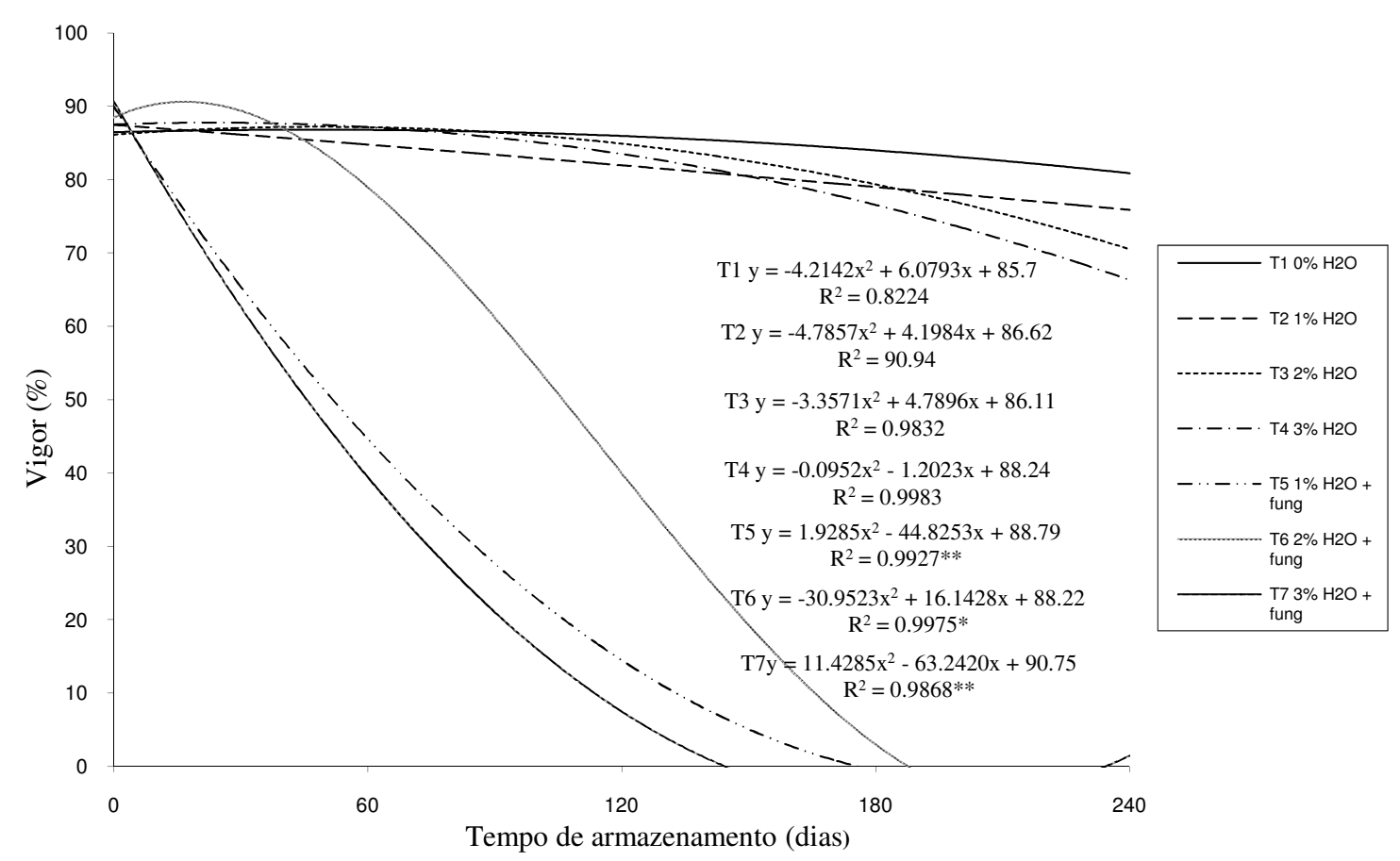

FIGURA 3. Porcentagem de plântulas normais no teste de frio com sementes de arroz, cultivar EL PASO 144, lote 1 , armazenadas hermeticamente durante oito meses $\mathrm{a} \pm 22^{\circ} \mathrm{C}$.

Na Figura 4 verifica-se a mesma tendência, ou seja, sementes tratadas com fungicidas apresentam maior vigor inicial, perdendo esta característica mais rapidamente que as não tratadas ao longo do armazenamento.

Os fungos observads no teste de sanidade das sementes foram classificados em três grupos distintos: fungos de campo (Fusarium spp, Alternaria sp, Gerlachia sp, Dreschlera sp, Curvularia sp.) fungos de armazenamento (Aspergillus spp e Penicilluim sp.) e outros (não patogênicos e/ou contaminantes), cujos resultados de incidência encontram-se na Tabela 3. Observa-se que o lote 2 apresenta um índice de contaminação mais alto nos três grupos de fungos quando comparado com o lote 1, destacando-se especialmente o gênero Gerlachia (21\%), o que contribui para que a incidência total de fungos nesse lote tenha sido de $60 \%$, enquanto no lote 1 foi de apenas $8 \%$.

Pela Tabela 4 verifica-se que, aos 180 dias de armazenamento, houve redução do índice de incidência para a maioria dos fungos em ambos lotes. Tais resultados também foram relatados por Sofiatti e Schuch (2005), 
trabalhando com duas cultivares de arroz (EL PASO 144 e IRGA 417), onde a aplicação de fungicida reduziu acentuadamente a severidade de doenças fúngicas. Cabe ressaltar que o efeito benéfico do tratamento com fungicida foi favorecido em razão da baixa incidência inicial de fungos do lote 1 . O lote 2 (Tabela 5) também apresentou redução do potencial do inóculo associado às sementes, principalmente nos tratamentos com calda fungicida, havendo inclusive expressiva redução de fungos de campo durante o armazenamento. Este fato foi observado por Valarini et al. (1990) em sementes de arroz, onde que após dois meses de armazenamento houve redução considerável na incidência da maioria dos fungos presentes. Os autores atribuíram essa redução à perda de viabilidade do inóculo ao longo do período de armazenamento. Macedo et al. (2002) e Quagliariello et al (1997) também constataram tendência de diminuição na incidência dos fungos com o decorrer do tempo em sementes de arroz. Já Henning et al. (1997) relataram que, apesar do fungo perder a viabilidade durante o armazenamento, o tratamento das sementes com misturas de fungicida sistêmico e de contato se torna necessário para garantir a erradicação do patógeno e proteger a semente contra fungos de solo.

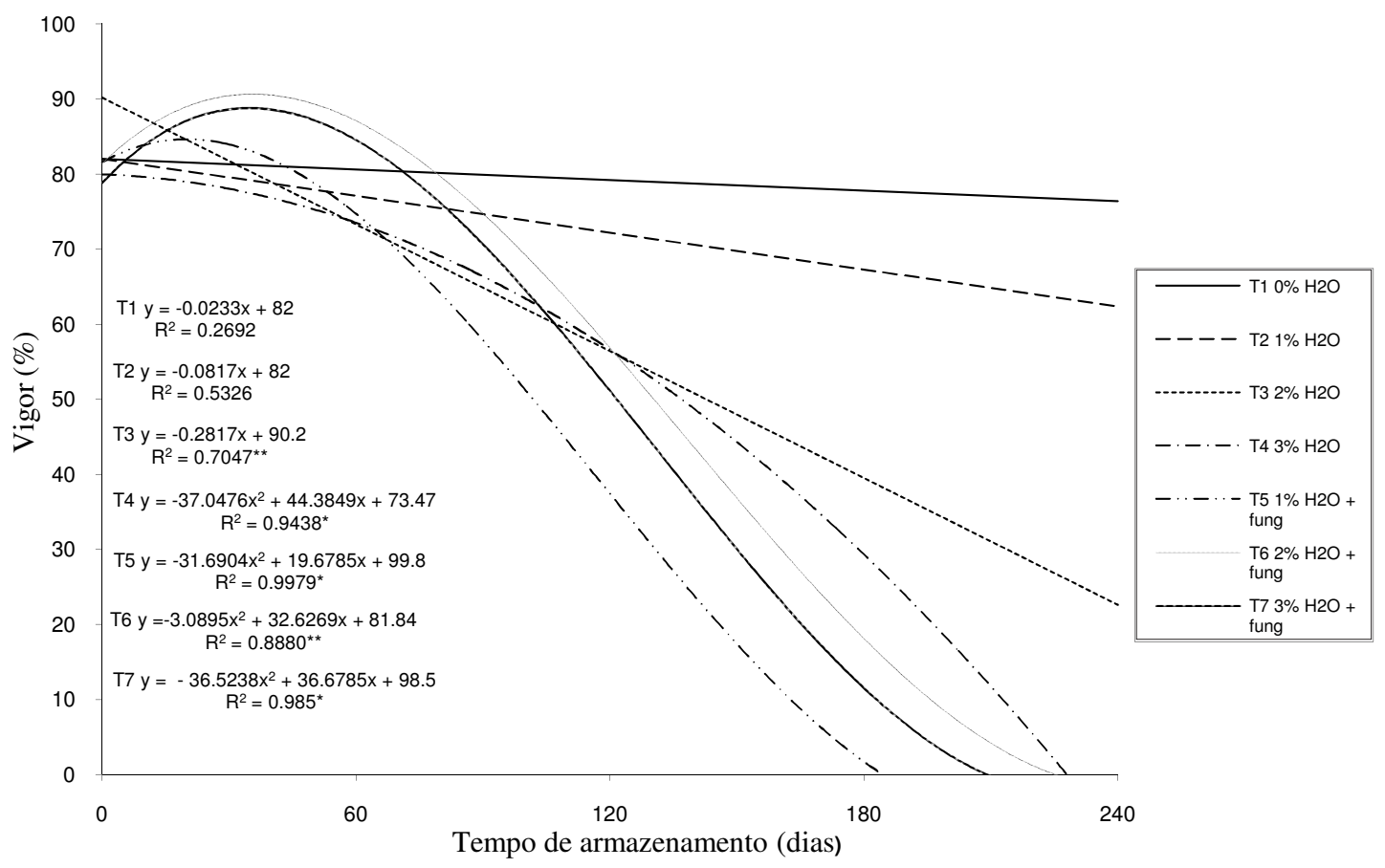

FIGURA 4. Porcentagem de plântulas normais no teste de frio de sementes de arroz, cultivar EL PASO 144, lote 2, armazenadas hermeticamente durante oito meses $\mathbf{a} \pm 22{ }^{\circ} \mathrm{C}$.

TABELA 3. Porcentagem inicial de incidência de fungos em dois lotes de sementes de arroz cultivar EL PASO 144.

\begin{tabular}{ccccccccc}
\hline \multicolumn{10}{c}{ Gêneros de fungos } \\
\hline Lotes & Fus. & Gerl. & Dresch. & Alter. & Curv. & Armaz. & Outros & TOTAL \\
Lote 1 & 1 & 1 & 0 & 2 & 1 & 1 & 2 & 8 \\
Lote 2 & 6 & 21 & 2 & 10 & 4 & 7 & 10 & 60 \\
\hline
\end{tabular}

Fus. $=$ Fusarium spp.; Gerl. $=$ Gerlachia sp.; Dresch $=$ Dreschlera spp; Alter $=$ Alternaria sp.; Curv. $=$ Curvularia sp.; Armaz. $=$ Penicillium sp e Aspergillus spp. 
TABELA 4. Porcentagem dos fungos de campo (C), armazenamento (A) e outros (O) durante o armazenamento de sementes de arroz, lote 1, cultivar EL PASO 144, submetidos a tratamentos fungicida.

\begin{tabular}{ccccccccccccc}
\hline \multicolumn{10}{c}{ Período de Armazenamento - lote 1 } \\
\hline \multicolumn{10}{c}{ Pré-armazenamento } & \multicolumn{10}{c}{ 60 dias } & \multicolumn{1}{c}{120 dias } & \multicolumn{3}{c}{180 dias } \\
\hline Tratamentos & C & A & O & C & A & O & C & A & O & C & A & O \\
\hline T1 & 5 & 1 & 2 & 3 & 0 & 2 & 0 & 0 & 0 & 1 & 0 & 0 \\
T2 & 3 & 1 & 2 & 3 & 0 & 1 & 0 & 0 & 0 & 0 & 0 & 0 \\
T3 & 5 & 1 & 3 & 3 & 1 & 2 & 2 & 0 & 1 & 1 & 1 & 0 \\
T4 & 7 & 1 & 4 & 2 & 1 & 1 & 1 & 1 & 3 & 0 & 3 & 1 \\
T5 & 10 & 5 & 0 & 0 & 0 & 0 & 0 & 0 & 0 & 0 & 0 & 0 \\
T6 & 1 & 10 & 0 & 0 & 0 & 0 & 0 & 0 & 0 & 0 & 0 & 0 \\
T7 & 1 & 2 & 0 & 0 & 0 & 0 & 0 & 0 & 0 & 0 & 0 & 0 \\
\hline
\end{tabular}

TABELA 5. Porcentagem dos fungos de campo (C), armazenamento (A) e outros (O) durante o armazenamento de sementes de arroz, lote 2, cultivar EL PASO 144 submetidos a tratamentos fungicida.

\begin{tabular}{ccccccccccccc}
\hline \multicolumn{10}{c}{ Período de Armazenamento - lote 2 } \\
\hline \multicolumn{10}{c}{ Pré-armazenamento } & \multicolumn{10}{c}{ 60 dias } & \multicolumn{1}{c}{120 dias } & \multicolumn{3}{c}{180 dias } \\
\hline Tratamentos & C & A & O & C & A & O & C & A & O & C & A & O \\
\hline T1 & 43 & 7 & 10 & 22 & 1 & 3 & 17 & 6 & 1 & 3 & 3 & 0 \\
T2 & 63 & 9 & 15 & 6 & 1 & 1 & 3 & 2 & 0 & 2 & 4 & 1 \\
T3 & 57 & 10 & 16 & 5 & 4 & 0 & 2 & 3 & 0 & 1 & 3 & 1 \\
T4 & 56 & 17 & 16 & 7 & 10 & 0 & 6 & 11 & 0 & 2 & 6 & 2 \\
T5 & 6 & 7 & 1 & 2 & 2 & 0 & 1 & 2 & 1 & 0 & 1 & 0 \\
T6 & 15 & 8 & 2 & 3 & 3 & 0 & 1 & 3 & 0 & 1 & 2 & 0 \\
T7 & 16 & 4 & 3 & 2 & 5 & 0 & 3 & 3 & 1 & 0 & 1 & 0 \\
\hline
\end{tabular}

Em relação à avaliação da atividade das enzimas, a ausência de diferença entre tratamentos foi observada para todos os zimogramas; desta forma, não foi possível detectar o efeito do fungicida na expressão das enzimas nas sementes de arroz.

\section{CONCLUSÕES}

$\mathrm{O}$ tratamento de sementes de arroz com fungicida Carboxin-Thiran na dose de $300 \mathrm{~mL}$ por $100 \mathrm{~kg}$, promove aumento na porcentagem de germinação quando a avaliação é feita imediatamente após o tratamento.

O tratamento de sementes com o fungicida CarboxinThiran reduz a incidência dos fungos Fusarium spp, Alternaria spp, Gerlachia sp, Bipolaris sp, Dreschelera sp,
Curvularia sp, associados às sementes de arroz.

A alta umidade associada ao fungicida aplicado acelera redução da qualidade das sementes armazenadas em ambientes herméticos.

Não foi possível detectar o efeito do fungicida na expressão das enzimas das sementes viáveis.

\section{REFERÊNCIAS}

ALFENAS, A.C. Eletroforese de isoenzimas e proteínas afins. Viçosa: UFV, 1998. 574p.

BRASIL. Ministério da Agricultura e Reforma Agrária. Secretaria NacionaldeDefesa Agropecuária.Departamento Nacional de Produção Vegetal. Coordenação de Laboratório Vegetal. Regras para Análise de Sementes. 
Brasília, DF, 1992. 365p.

EMBRAPA. Importância econômica, agrícola e alimentar do arroz . In.: Cultivo de Arroz Irrigado no Brasil, 2005. Disponível em: <http://www.cnpaf.embrapa. br>. Acesso 3 jan. de 2007.

HENNING, A.A.; KRZYZANOWSKI, F.C.; FRANÇANETO, J.B.; COSTA, N.P.; CAMARGO, T.V. Embalagem de sementes de soja para armazenamento em regiões tropicais e subtropicais. Informativo ABRATES,v.5, n.2, p.47, 1995.

HENNING, A.A.; YORINORI, J.T.; FRANÇA- NETO, J.B.; GARRIDO, R.B.O. Ocorrência de Cercospora kikuchii em sementes básicas de soja, no Brasil. In.: Congresso Brasileiro de Sementes, 10, Foz do Iguaçu, 1997. Informativo ABRATES, v.7, n.1/2, 1997, 161p.

KRZYZANOWSKI, F.C.; VIEIRA, R.D.; FRANÇA NETO, J.B. Vigor de sementes e testes. Londrina: ABRATES, 1999. 218p.

MACEDO, E.C.; GROTH, D.; SOAVE, J. Influência da embalagem e do armazenamento na qualidade fisiológica de sementes de arroz. Revista Brasileira de Sementes, v.21, n.1, 2002, p.67-75.

MACHADO, A.A.; CONCEIÇÃO, A.R. WinStat, sistema para análise estatística para Windows. Versão 2.0. Pelotas: UFPel/NIA. 2003.

MARCOS-FILHO, J.; SOUZA, F.H.D. Conservação de sementes de soja tratadas com fungicidas. Anais... da ESALQ, v.40, n.1, 1983, p.181-201.

MENTEN, J.O.M. Tratamento de sementes. In: SOAVE, J; OLIVEIRA, M.R.M. \& MENTEN, J.O.M. (Ed.). Tratamento químico de sementes. In: SIMPÓSIO BRASILEIRO DE PATOLOGIA DE SEMENTES, 4., Gramado, 1996. Anais... Campinas: Fundação Cargill, 1996. p.3-23.
MIURA, L. Doenças. In: EPAGRI Arroz irrigado: sistema pré-germinado. Florianópolis: Epagri/ GMC, 2002, p.203227.

NEERGAARD, P. Incubation tests. In: Seed Pathology. London: Macmillan Press, 1977, 839p.

PUZZI, D. Abastecimento e armazenagem de grãos. Campinas: Instituto Campineiro de Ensino Agrícola, 1986, $603 p$.

QUAGLIARIELLO, V.; PANIZZI, R.C.; VIEIRA, R.D.; FORNASIERI-FILHO, D. Incidência, transmissão e controle de Rhyncosporium oryzae em sementes de arroz. In: Congresso Brasileiro de Sementes, 10., Foz do Iguaçu, 1997. Informativo Abrates, v.7, n.1/2, p.131, 1997.

RIBEIRO, A.S. Tratamento de sementes com fungicidas. Revista Anual de Patologia de Plantas. v.4, 1996, 415p.

SCANDALIOS, J.G. Genetic control of multiple molecular forms of enzymes in plants: a review. Biochemical Genetics, v.3, p.37-39, 1969

SOFIATTI, V.; SCHUCH, L.O.B. Efeitos de regulador de crescimento e controle químico de doenças na qualidade fisiológica e sanitária de sementes de arroz. Revista Brasileira de Sementes, v.27 n.2,p.102-110, 2005.

VALARINI, P.J.; VECHIATO, M.H.; LASCA, C.C. Sobrevivência de fungos asociados a sementes de arroz (Oryza sativa L.) em duas condições de armazenamento. Fitopatologia Brasileira, v.15, n.3, p.173-176, 1990.

ZAPATA, J.C. Efecto del manchado del grano de arroz sobre algunos estados de desarollos de la planta de arroz. Arroz, v.34, n.338, 1985, p.22-26.

ZORATO, M.F., HENNING, A.A. Influência de tratamentos fungicidas antecipados, aplicados em diferentes épocas de armazenamento, sobre a qualidade de sementes de soja. Revista Brasileira de Sementes, v.23, n.2, p.236-244, 2001. 